Published in final edited form as:

J Autism Dev Disord. 2019 June ; 49(6): 2243-2256. doi:10.1007/s10803-019-03901-9.

\title{
Fifteen-Year Prospective Follow-Up Study of Adult Outcomes of Autism Spectrum Disorders Among Children Attending Centers in Five Regional Departments in France: The EpiTED Cohort
}

\author{
Amaria Baghdadli ${ }^{1,2,3,4}$, Cécile Rattaz ${ }^{2}$, Cécile Michelon ${ }^{2}$, Eric Pernon ${ }^{2}$, Kerim Munir $^{5}$ \\ ${ }^{1}$ Département de Psychiatrie, Centre Universitaire Hospitalier (CHU) de Montpellier, 34000 \\ Montpellier, France \\ ${ }^{2}$ Centre de Ressources Autisme Languedoc-Roussillon, CHU Montpellier, 39 Avenue Charles \\ Flahaut, 34295 Montpellier, France \\ ${ }^{3}$ Centre de Recherche en Épidémiologie et Santé des Populations, U1178, INSERM, Paris, \\ France \\ ${ }^{4}$ Ecole de Médecine, Université de Montpellier, Montpellier, France \\ ${ }^{5}$ Developmental Medicine Center, Boston Children's Hospital, Harvard Medical School, Boston, \\ MA, USA
}

\begin{abstract}
There is limited data on long-term outcome of ASD with co-occurring intellectual disabilities (ID) and challenging behaviours in France. The EpiTED period cohort is a 15 years longitudinal study of the developmental trajectories of 281 children initially recruited at mean age of 5 years. Two contrasted developmental trajectories were identified. Low cognitive level, absence of language, and higher ASD scores at baseline were predictive of low growth at follow-up. As adults the participants were predisposed to persistent co-occurring challenging behaviours as well as underlying ID impacting their ability to function independently. The results underscore the need for development of services and supports for adults with ASD in France who may also have already lacked access to adequate interventions and support services.
\end{abstract}

\section{Keywords}

Autism spectrum disorders; Cohort; Longitudinal; Long-term follow-up; France

\footnotetext{
Amaria Baghdadli, rech-clinique-autisme@chu-montpellier.fr.

Author Contributions AB was involved in the study design and methods, data collection, interpretation of results, writing, and revision of the initial draft. EP was involved in the study design and methods and data collection. CM and CR were involved in data analysis, interpretation of results, writing, and revision of the draft. $\mathrm{KM}$ was involved in the interpretation, writing, and revision of the draft. All the authors have critically revised this article and approved the final version to be published.

Conflict of interest The authors declare that they have no conflict of interest.

Ethical Approval This study was approved by the Medical ethical committee and the National Commission for Computing and Liberties (CNIL. number $1585321 \mathrm{v} 0$ ).

Informed Consent Informed consent was obtained from all individual participants included in the study.

Publisher's Note Springer Nature remains neutral with regard to jurisdictional claims in published maps and institutional affiliations.
} 
Autism spectrum disorder (ASD) is a neurodevelopmental syndrome defined by deficits in social communication, as well as restricted, repetitive patterns of behaviours, interests, or activities (American Psychiatric, 2013; Centers for Disease Control and Prevention (CDC), 2014). The symptoms of ASD are highly heterogeneous, present in early childhood, and limit an affected person's adaptive functioning across the lifespan. Understanding heterogeneity of outcomes of ASD is particularly salient as it can help guide policy and develop better targeted interventions to improve prognosis. It is generally assumed that there is a wide range of long-term outcome trajectories. To date, most studies examining out-come of ASD have been cross-sectional in design with only few studies adopting a developmental perspective examining changes in symptom profiles at various points across the lifespan (Steinhausen et al. 2016).

Phenotypically well characterized and large scale follow-up studies of ASD represent important opportunities to study the diversity of clinical trajectories and to examine temporal change in symptoms and dynamic interactions among risk and protective factors. In a systematic review of 25 longitudinal follow-up studies, outcome of ASD was noted to be highly variable (Magiati et al. 2014). When focusing on adaptive abilities, all the studies reported at least some improvements in overall composite or age equivalent adaptive functioning scores (Gillespie-Lynch et al. 2012; McGovern and Sigman 2005; Szatmari et al. 2009). However, information regarding functioning in adulthood was provided in a format that allowed examination of change over time in only four studies. None of the studies examined the relationship between initial adaptive functioning in childhood and later adaptive functioning in adulthood.

The EpiTED cohort in France (acronym in French for Epidemiological study of outcome of children with pervasive developmental disorders) was a population-based study set-up 20 years earlier in order to examine the naturalistic outcomes of ASD among children recruited at 3-7 years of age (time 1, T1), and followed at ages eight (time 2, T2), 15 (time 3, T3) and 20 years (time 4, T4), collecting socio-demographic, clinical, developmental and interventional data at each stage. The cohort entailed comprehensive and longitudinal assessments of the index children using gold-standard diagnostic measures of ASD, and standardized assessments of cognition, language and behavior. An impetus for the inception of the EpiTED cohort was that children with mild or moderate symptoms of ASD in France were rarely being referred for multidisciplinary diagnosis, and those recruited for clinical studies were in majority with more prototypical severe clinical profiles. An epidemiological approach to better examine developmental trajectories of ASD was therefore paramount. The EpiTED cohort, because of its unique prospective design, offered an opportunity to explore important questions related to ASD outcomes during adulthood including aspects related to co-occurrence of intellectual disability (ID) and challenging behaviours, as well as parental quality of life (QoL).

With respect to challenging behaviours across the lifespan many questions remained regarding the type and time course of change (Billstedt et al. 2007; Chowdhury et al. 2010; Murphy et al. 2005; Shattuck et al. 2007). With respect to QoL, studies suggested that parental QoL is of particular import in ASD outcomes (Eapen and Guan 2016), and is also related to unmet care needs, social exclusion, lesser degree of social support networks, as 
well as co-occurring challenging behaviours (Craig et al. 2016; Davis and Carter 2008;

Schieve et al. 2007).

The main goal of the EpiTED prospective follow-up study was to identify the long-term outcome trajectories of a large cohort of children with ASD with co-occurring levels of severity of ID with associated cognitive, communication, and adaptive impairments. The EpiTED cohort represents a unique data source for an important period of neglect in autism services in France and comprises a unique population of children with ASD who were referred to public hospital centres in France. The aim of the this paper is to present and summarize the main results of the EpiTED study over a 15 years follow-up period providing a topography for clinicians, researchers and policy makers, highlighting specific developmental trajectories of children with ASD with co-occurring levels of severity of ID and challenging behaviours, and describing their impact on parental QoL.

\section{Cohort Description}

\section{Setting, Recruitment and Eligibility}

The multicenter EpiTED cohort involved child and adolescent psychiatry services and ASD evaluation clinics located in public hospitals in five Departments in France (namely, Languedoc-Roussillon, Rhône-Alpes, Bretagne, Alsace and Others). Prior to the enrollment phase, common training sessions were conducted to harmonize the diagnosis of ASD and to distinguish it from non-ASD neurodevelopmental disorders. Regular meetings across collaborating sites were organized during the enrollment phase to improve clinical agreement. To ensure this, the staff at the centers in the five Departments received standardized training in terms of common assessment techniques and psychological measures.

The inclusion criteria in the EpiTED cohort were: (a) index child age below 7 years; (b) parental informed consent; (c) diagnosis of childhood autism, atypical autism, or Asperger Syndrome according to ICD-10 criteria (atypical autism corresponded to at least two domains of impairment according to ICD-10 criteria) (World Health Organization 1993) (autism will be subsequently referred to as ASD unless specifically signifying subtype). All diagnoses were validated by two independent, experienced child and adolescent psychiatrists among the research staff (including AB), on the basis of medical records, as well as videotaped observations during enrollment. Subjects for whom a consensual diagnosis could not be obtained or those for whom the date of appearance of ICD-10 autism symptoms emerged after 3 years were not enrolled.

Between 1997 and 1999, among 362 eligible children, 281 with ASD (77\%) aged between 3 and 7 years fulfilled the research inclusion criteria (T1); 62 children were excluded as they did not meet research inclusion criteria; 19 children (families) had moved away prior to enrollment and were also excluded.

The study procedures and protocols were approved by the Local Human Subject Protection Committee and National Commission for Computing and Liberties (CNIL). The EpiTEDcohort is recorded on AVIESAN Epidemiology-France portal. 


\section{Follow-Up}

The index children were followed prospectively over 15 years with four assessment points: ages 5 (T1), 8 (T2), 15 (T3), and 20 (T4) years (see flow chart, Fig. 1). At T2, from 2000 to 2002, 219 of children were reassessed; at T3, from 2007 to 2009, 152 adolescents were reassessed; and at T4, from 2012 to 2015, 106 young adult subjects were reassessed.

The multicenter data collection involved considerable efforts by the coordination team for harmonization of follow up visits, mailings, annual training sessions, as well as in terms of consensus building of study procedures and use of standardized instruments. Historically, the child and adolescent psychiatry units were the only public centers authorized to diagnose and follow-up preschool children with ASD in France in the mid-1990s. In ensuing project period, follow-up sites were diversified with development of other centers in France. To ensure coherence, the EpiTED team was responsible for the T4 follow-up undertaking visits where participants lived.

All the participant families were annually kept abreast of progress as well as relevant study news by means of a bulletin. A postal survey was conducted before each of the four collection times in order to give to the coordinating team an estimate of the potential participation rate and to update the addresses and telephone numbers of the participants. The loss to follow-up at each stage was about $20 \%$. The subject characteristics at T1, T2, T3 or T4 were similar in terms of age, severity of ASD symptoms, adaptive behaviours, presence of speech, parent socio-economic status, co-occurrence of epilepsy, as well as associated congenital and/or chromosomal abnormalities (see Table 1).

\section{Outcome Measurements and Evaluated Variables}

Data were recorded using standardized and validated tools. Descriptions of data collected at inception and the three follow-up times are shown in Table 2.

The primary outcome measures of the study were the standard scores in the three domains of the vineland adaptive behavior scale (VAB-S) (Sparrow et al. 1984). This scale is widely used to assess adaptive skills in different areas (daily living, communication, socialization and motor skills) in individuals from birth to adulthood including those affected by intellectual disabilities or ASD. VABS scores recorded at each of the follow-up times were used to identify developmental trajectories in communication, socialization, and daily living skills.

Socio-demographic and lifestyle data were collected by self-report using a parent questionnaire regarding marital, socio-occupational status, and child services (e.g., interventions delivered in typical and specialized settings, numbers of hours and service type). At T4, additional data were recorded about parental supports, e.g., financial, as well as parent training.

Data about developmental milestones, e.g., age at sitting, walking, and so on, were collected by parent report, or review of elicited medical records with parental consent.

Anthropometric data were recorded including weight (measured digitally to the nearest 0.1 $\mathrm{kg}$ ), height (measured to nearest $\mathrm{cm}$ using a board), and umbilical perimeter (to nearest $\mathrm{cm}$ ). 
Standardized procedures were used to conduct the psychological and psychiatric assessments. At T1, a diagnostic interview was conducted to confirm the diagnosis using Autism Diagnostic Interview, Revised edition (ADI-R) (Rutter et al. 2003); at T3 and T4, the Autism diagnostic observation schedule (ADOS) were completed (Lord et al. 2002).

Expressive speech was assessed on the basis of composite items according to three levels: (1) spontaneous, functional with sentences composed of three or more words; (2) at least five different words with consistent use; and (3) fewer than five words. At T4, the receptive vocabulary level was assessed with the Peabody test (Échelle de Vocabulaire en Images Peabody EVIP) (Dunn et al. 1993).

A "best estimate" intellectual functioning level was derived at each step for each participant from the available assessments at each stage, following the methodology used by Howlin, et al. (2014). The performance IQ (PIQ) was recorded when it was possible to administer a standardized verbal test; in other cases, when the participants could not understand test instructions or requirements, a developmental quotient (DQ) was calculated. The Best Estimate DQ at T1 was appraised from the WISC/WISC-R or WPPSI (Wechsler 1949, 1967, 1974) ( $\mathrm{n}=4)$, KABC (Kaufmann 1983) $(\mathrm{n}=10)$, PEP-R (Schopler et al. 1990) $(\mathrm{n}=27)$ and (Brunet-Lézine scales 1997) $(\mathrm{n}=35)$; at T2, from Brunet-Lézine $(\mathrm{n}=23), \mathrm{KABC}(\mathrm{n}=12)$, PEP-R $(n=12)$, WISC $(n=8)$, WPPSI $(n=3)$, or EDEI-R $(n=2)$; at T3, from WISC-4 (QIP, $n=37$ ), WPPSI (PIQ, $n=15)$, or KABC $(n=4)$; and at T4, from the WAIS-IV (Wechsler 2008) (PIQ, $n=33$ ), WPPSI (PIQ, $n=19$ ), or WISC-4 (PIQ, $n=6$ ), similar to when they were children. For some children or adults who had a very low cognitive level, a full administration of the psychological test was not possible because of difficulties to understand the test instructions or because of challenging behaviors (T1: $\mathrm{N}=13 ; \mathrm{T} 2: \mathrm{N}=$ 46; T3: $N=50 ; \mathrm{T} 4: \mathrm{N}=38$ ). For these participants, the clinical psychologist partially completed the test during the assessment and fulfilled the missed items of the tests (PEP-R and Brunet-Lézine) based on videotaped observations recorded during the ADOS and on parental information. The level of intelligence was classified into four categories: no ID (DQ $\geq 70$ ), moderate ID (55 $\geq \mathrm{DQ}>70)$, mild ID (40 $\geq \mathrm{DQ}>55)$, and severe ID (DQ < 40).

ASD symptom severity was assessed using the total score of the childhood autism rating scale (CARS) (Eric Schopler et al. 2002), with scoring based on a 20 min and standardized video clip of the child interacting with an adult. A self-administered questionnaire was used to collect data about behavioral problems using the aberrant behavior checklist (ABC) (Aman et al. 1985) with behavioral domains including: (I) irritability; (II) lethargy; (III) stereotypy and self-injury; and (IV) hyperactivity.

The impact of ASD on parental QoL was measured using the self-administered parentaldevelopmental disorder-QoL scale (Par-DD-QoL) (Baghdadli et al. 2014) containing three dimensions: emotions, daily disturbance and global QoL.

\section{Statistical Analysis}

A descriptive analysis of data was carried out at regular intervals in order to check the homogeneity of the data collection. Descriptive statistics were computed using means and standard deviations or median and Inter-Quartile (25-75th Quartile) for quantitative 
variables, and proportions for categorical variables (T1-T4). Multivariate analysis was aimed to identify outcome trajectories in the population defined by patients who have at least three collection times. To identify adaptive trajectories (communication, daily living skills, and socialization scores from VABS), we used the semi-parametric group-based trajectory modeling technique, Latent class growth analysis (Jones and Nagin 2007; Nagin and Nagin 2005; Nagin and Odgers 2010; Nagin and Tremblay 2005), a form of growth mixture modeling. This technique is suitable for cohorts with longitudinal designs. Trajectories were examined with the SAS (version 9.1) PROC TRAJ program (Jones et al. 2001). A censored normal distribution was used as the basis of model estimation. First, the identification of prognostic factors influencing the out-come was performed using comparison tests for continuous variables (Student's $t$ test or Mann-Whitney/KruskalWallis/Wilcoxon tests, depending on the distribution) and Chi square Test for categorical variables. When the conditions of validity of the Chi square were not met, the Fisher exact test was utilized. Second, logistic or polytomic regressions were conducted to highlight the respective influence of each covariate on outcome. The significance level used was set at $5 \%$. Statistical analyses were performed using SAS version 9.1 (SAS Institute, Cary, North Carolina).

\section{Main Findings}

\section{Cross-Sectional and Longitudinal Characteristics of the Sample}

The diagnosis of ASD was stable (see Table 3): 94 (88.7\%) subjects received a diagnosis of childhood autism and 12 subjects a diagnosis of atypical autism at T1; at 15 years follow up (T4), $82.6 \%$ of the cohort remained above the ADOS ASD threshold; $5.4 \%$ of the cohort lowered their ADOS scores under the ASD threshold; $12 \%$ of the cohort became "atypical autism". Whereas the ASD diagnosis was remarkably stable between T1 and T2 follow up stages, most diagnostic changes occurred between $\mathrm{T} 2$ and $\mathrm{T} 3$.

The ratio of participants without ID ranged between 7.5 and 22.5 according to measurement steps. Among the subjects with childhood autism, 59.6\% were non-verbal at T1, with 39\% remaining non-verbal at T4. With respect to comorbid ID, most changes occurred between 4 and 8 years of age. The proportion of children with either word/sentence language at T4 was $61 \%$.

The ratio of combined moderate and severe ID (IQ 20-25 to 50-55) measured by "best estimate" assessment of intellectual functioning was stable across time (around 80\%), but the ratio of moderate ID (IQ 35-55 to 50-55) decreased from 27 to 5\%, while that of severe ID (20-25 to 35-40) increased from 49 to $78.2 \%$ between T1 and T4.

\section{Long-Term Adaptive Trajectories}

We charted the developmental trajectories of adaptive functioning in socialization, communication and daily living skills from the VABS over the follow up period (T1-T4). A non-parametric group based trajectory analysis was used and the best fitting model was a two-group trajectory for all three dependent variables. The first stage of this longitudinal development, including an initial period of 3 years of follow-up (between T1 and T2) 
showed that a high proportion of the children with ID did not change over time but that the intellectual, linguistic, and adaptive functioning at preschool-age was incompletely predictive of their outcome. When examining the adaptive trajectories built on the basis of VABS from preschool age (T1) to young adulthood (T4), we found that about $80 \%$ of the subjects had a very slow growth between T1 to T4, and that $20 \%$ had a faster growth rate (Baghdadli et al. 2018). Participants belonging to the slow growth group, who represented the majority of the cohort, had a relatively flat and linear slope, with a low adaptive functioning at adulthood in the domains of communication, daily living skills, and socialisation. For participants in the high growth group, communication scores increased sharply, and linearly, whereas socialisation and daily living skills followed a quadratic trend, with an accelerating improvement rate between $\mathrm{T} 3$ and $\mathrm{T} 4$ in comparison to that observed between T2 and T3 (see Fig. 2).

High growth group; lower CI 95\%; - . . . - - upper CI 95\%

The variables collected at $\mathrm{T} 1$ that predicted the developmental trajectories in the domains of communication, daily living skills, and socialisation, were the degree of autism and the intellectual level (Baghdadli et al. 2012, 2018).

\section{Challenging Behaviors}

The challenging behaviors were studied using the Aberrant Behavior Checklist (ABC). At adolescence (T3), cluster analysis was conducted in order to identify challenging behaviors patterns and to examine if these patterns were related to developmental trajectories. The characteristics of the four clusters identified were: (1) low scores in the four ABC domains, (2) high scores in irritability and hyperactivity, (3) medium scores in the four domains, and (4) medium level of irritability, and high scores in stereotypy, lethargy and hyperactivity (Baeza-Velasco et al. 2014). These patterns were significantly linked to the adolescents' adaptive behavior trajectories. Most adolescents with a high trajectory (87\%) were found in clusters one and three, whereas adolescents with a low trajectory were equally distributed in the four clusters. We also found that more than one-third of adolescents with ASD in our sample displayed self-injury, which was frequently associated with other challenging behaviors and was related to the severity of the autism symptoms, adaptive skills, intellectual functioning, and language level (Rattaz et al. 2015). The main risk factor for co-occur-ring self-injurious behavior at adolescence was severity of ASD symptoms. High cognitive level during childhood was found to be a protective factor whereas at adolescence, the main protective factor was communicative abilities.

At adulthood (T4), we found that the presence of challenging behaviors was related to the young adult's cognitive and language level, ASD symptom severity, as well as co-occurring gastrointestinal (GI) and sleep disorders (see Table 4) (Rattaz et al. 2018). The main risk factor for challenging behaviors was ASD symptom severity. The level of language impairment was a significant predictor of co-occurring SIB. GI disorders were a significant predictor of stereotypy. The change in behavior topography from adolescence to early adult years corresponded with decreased parent report of hyperactivity, but no significant decrease in parent reports of irritability, stereotypy, lethargy and SIB. 


\section{Parental Quality of Life}

The impact of ASD on parental QoL during adolescence and adulthood was examined using Par-DD-QoL (Baghdadli et al. 2014).

At adolescence (T3), 65\% (99/152) of parents of adolescents with ASD reported a moderate or high impact on their QoL. A polytomic regression identified an increase in aberrant behavior scores as the factor having the highest impact on parental QoL. Protective factors were also identified: an increase in daily living skills, communication and intellectual level scores and a higher number of siblings. We also examined the occurrence and timing of separation of parents raising children with ASD over a 10-year period. The results showed that after 10 years of follow-up $74.8 \%$ of the couples remained together $(n=89)$, representing a separation rate of $25.2 \%$ (vs. $28 \%$ in the French general population) (Vanderschelden 2006).

At adulthood (T4), 67\% of parents of young adults with ASD (70/106) reported a moderate or high impact on their QoL. The perceived impact of ASD on parental QoL was related to the young adults' level of adaptive skills, as well as to symptom severity and the presence of challenging behaviors, which appeared to be the main risk factor. The proportion of parents who perceived a high impact, moderate impact or no impact on their QoL remained stable between adolescence and adulthood. However, this stability was observed only at the group level but not at an individual level as many parents moved from one category to another between the two collection times, e.g., perceived no impact of ASD on QoL at T3, and a moderate impact at $\mathrm{T} 4$. The study of change between adolescence and early adulthood showed that parents whose children had a decrease in challenging behaviors perceived a decreased impact on their QoL.

\section{Discussion}

The EpiTED is a unique prospective cohort of children with well-characterized ASD referred to five Departments in France. At the time of the cohort's inception, the participating centers were the only public sites diagnosing and treating preschool children with ASD in the country. Although the cohort exhibited considerable rate of co-occurring ID, it must be noted that 20 years ago early diagnosis of high functioning children with ASD and interventions for them were not the norm in France. Therefore, children with ASD with more severe co-occurring levels of ID, communication, and adaptive impairments, so identified, were more likely to be referred to the study collaborating sites. Among the 106 study participants at the four collection time points, diagnostic stability was dominant, but not constant, and associated with a general improvement of ASD characteristics. However, the emerging trend in intellectual abilities, as measured by the best estimate procedure, was more unstable, with an increase of severe ID from 49 to $78.2 \%$. This could result either from an actual decline of intellectual abilities, potentially and consequentially due to minimal exposure to educational interventions and learning opportunities (many children with ASD were historically excluded from mainstream education lacking access to support services), or alternatively as a result of lower performance scores on identical measures with advancing age, or both. 
While an improvement in adaptive skills measured by the VABS was the rule for the entire group, two contrasted developmental trajectories in adaptive functioning were identified. The majority of participants (around 80\%) followed a low-growth developmental trajectory, with the remainder following a high-growth trajectory. Again, for majority of participants, a lower cognitive level, absence of functional speech, and increased CARS scores at T1 predicted a low-growth trajectory in communication, socialization, and daily living skills. Other studies have reported a similar relationship with IQ, non-verbal mental age, ASD severity and speech (Bal et al. 2015; Smith et al. 2012; Szatmari et al. 2015). Nonetheless, in the absence of studies on long-term effect of intervention, one cannot decide if this poor outcome is intrinsic to a fraction of the ASD population, or an effect of absence of interventions or limited exposure to learning opportunities.

As regards co-occurring challenging behaviors, our results suggest that behavioral problems in children with ASD persist in early adulthood and are related to core symptom severity, levels of cognitive and language impairments, as well as medical comorbidities. The results also affirm that ASD symptom severity among adult subjects was a significant predictor of co-occurrence of challenging behaviors (Baghdadli et al. 2003, 2008). Another significant predictor was the presence of GI disorders. This is consistent with reports of a high correlation between the presence of pain and the frequency and severity of stereotypies (Courtemanche et al. 2016), as well as challenging behaviors in general (Chaidez et al. 2014). Nonetheless, these combined variables only explained at most $30 \%$ of the developmental variance observed in the study sample. Invariably, this means that other factors, not identified here, might explain the presence of challenging behaviors in adults with ASD. Additional research is needed to examine other influences, with particular relevance for the services and interventions in the community provided.

It is of interest that for children with ASD, the main risk factors for self-injurious behaviour (SIB) were ASD symptom severity and cognitive level (Baghdadli et al. 2003, 2008). In the present study, the symptom severity remained a significant risk factor, but language skills instead of cognitive level predicted the presence of SIB. One possible explanation for this might be that SIB at adulthood may reflect a relationship with communicative deficits. This finding emphasizes the crucial role of communicative abilities and the need for targeted behavioural interventions for children with ASD aiming at developing better communication in order to prevent as well as manage subsequent challenging behaviours.

The impact of having a child with ASD on parental QoL was strong with several implications not only on daily life but also on parental emotional well-being, lasting through adolescence through young adulthood. The results did not affirm that raising a child with ASD often leads to the breaking up of the parental relationship, as has been commonly believed. Overall, parental QoL at early adulthood appears to be mainly predicted by the presence of co-occurring challenging behaviours, whereas at adolescence parental QoL was also predicted by the children's adaptive level, namely in communication and daily living skills. Again, the impact of co-occurrence of challenging behaviours on family life argues for the importance of implementing specific interventions targeting them at a younger age. In a functional behavioural assessment perspective (O'neill and Jones 1997), challenging behaviours are described as a way to obtain reinforcement or escape a negative experience, 
which is most of the time related to poor communication. From our perspective, the best way to prevent subsequent development of adverse behaviours is to propose specific treatment aiming at the development of communicative abilities in the very early years. It is also crucial to provide parental training and disability support guidance as parental involvement and knowledge is key predictive factor of parental satisfaction and performance (Renty and Roeyers 2006). We can hypothesize that the participants of the EpiTED cohort had limited access to this type of interventions, as the educational approaches have considerably changed since the children were included in this follow-up study 20 years ago (Happé and Charlton 2012).

Finally, the EpiTED as a "period" cohort reflects the ASD diagnostic practices in France in the mid-1990s and in the ensuing two decades. High-functioning verbal individuals were frequently not given ASD diagnoses, due to the dominant use of alternative diagnoses in the French classification of mental health disorders (Classification Française des Troubles Mentaux de l'Enfant et de l'Adolescent, CFT-MEA), particularly for verbal subjects, and the dominant influence of psychoanalysis.

An important limitation of the EpiTED cohort therefore is that the prevalence of cooccurring challenging behaviours, ID, as well as associate medical comorbidity, including epilepsy cannot be representative of a contemporary profile of children with ASD that will be currently recruited from child and adolescent psychiatry services and ASD evaluation clinics in public centers. Nonetheless, the EpiTED cohort provides a distinctive portrait of French children with official diagnosis of ASD enrolled in public centers and how they fared over a 20-years follow-up as they became young adults. While there was improvement in their adaptive skills, the substantial social and communication difficulties among the children in the cohort tended to persist in adult-hood reflecting the salient effects of nonspecific, delayed or absent interventions. As adults the subjects in the EpiTED cohort were noted to be predisposed to persistent challenging behaviours impacting their ability to be independent and have acceptable QoL. As the Government of France is increasingly recognizing the widespread shortcomings in services and supports for children with ASD and their families, the current EpiTED analyses underscore the need for service provision for adults with ASD as an urgent policy priority. This is a unique and relevant finding not only for researchers and clinicians but for policy makers in planning for the next National Autism Plan.

\section{Future Directions}

The EpiTED study findings will be compared to other ASD prospective follow-up studies of children with ASD who have benefited from relatively more selective and intensive treatment methods and social supports. In this regard, the current team is coordinating a new multidisciplinary cohort study (ELENA) (Baghdadli et al. 2014) with the main goal to identify patterns of long-term developmental trajectories in a large sample of children and adolescents with ASD. 


\section{Strengths and Limitations}

The main strengths of the EpiTED cohort are: (1) prospective long-term follow up; (2) relatively large sample size; (3) unique opportunity to study multiple dimensions of ASD across the lifespan; (3) use of standardized instruments and observational measures of ASD and associated variables; (4) contribution to harmonisation of diagnosis and assessment procedures across collaborating departments in France; (5) development of multidisciplinary assessment across adolescence and adulthood; and (6) validation of new questionnaires in France such as parental-developmental disorders-quality of life scale (Par-DD-QoL).

The EpiTED findings need to be considered in the context of a number of important limitations: (1) majority of index children in the EpiTED cohort had severe forms of ASD that limits generalizability of findings to other ASD subtypes; nevertheless they were representative of children with ASD in mid-1990s attending public centres in France; (2) the rate of loss to follow-up patients was substantive and selection bias cannot be ruled out; while a reasonable attempt was made to ensure the that the final sample was not significantly different than that lost to follow up based on baseline variables, other intervening family variables may also affect attrition; nonetheless, baseline comparisons of available sociodemographic data on participating and non-participating children did not suggest any major differences at baseline (Table 2) and this attrition rate is similar to other long-term follow-up studies (Kinra et al. 2014); (3) use of standardized measures of IQ and use of ratio IQs may impact the shift to more severe levels of ID in T4 follow-up; and (4) there was insufficient study of the lifelong influence of environmental factors, such as any putative in-utero drug or pesticide exposures, and the absence of a wider biological collection;

\section{Collaboration}

Data analyses and publications were generated primarily by our team. The EpiTED research team is open to scientific collaborations and ancillary future studies. To learn more about the EpiTED cohort and consider potential collaborations, please contact the principal investigator of this study, Prof. Amaria Baghdadli (a-baghdadli@chu-montpellier.fr).

\section{Acknowledgments}

We wish to sincerely thank the participants and their families for their valuable and long-lasting collaboration and their confidence in our study. We also extend our thanks to the research teams for their support during the past 15 years. A special thought to Florine Dellapiazza and to Colette Boy for their help with the literature review.

Funding This work was supported by grants from the Orange Foundation, and the French national health institute (PHRC 1997 \& 2007 and ANR Blanc).

\section{References}

Aman MG, Singh NN, Stewart AW, \& Field CJ (1985). The aberrant behavior checklist: A behavior rating scale for the assessment of treatment effects. American Journal of Mental Deficiency, 89(5), 485-491. [PubMed: 3993694]

American Psychiatric Association. (2013). Diagnostic and statistical manual of mental disorders (DSM-5®): Washington, DC: American Psychiatric Publishing.

Baeza-Velasco C, Michelon C, Rattaz C, \& Baghdadli A (2014). Are aberrant behavioral patterns associated with the adaptive behavior trajectories of teenagers with Autism spectrum disorders? Research in Autism Spectrum Disorders, 8(3), 304-311. 
Baghdadli A, Assouline B, Sonie S, Pernon E, Darrou C, Michelon C, Picot MC, Aussilloux C, Pry R (2012). Developmental trajectories of adaptive behaviors from early childhood to adolescence in a cohort of 152 children with Autism spectrum disorders. Journal of Autism and Developmental Disorders, 42, 1314-1325. 10.1007/s10803-011-1357-z. [PubMed: 21928042]

Baghdadli A, Michelon C, Pernon E, Picot M-C, Miot S, Sonié S, Rattaz C, Mottron L (2018). Adaptive trajectories and early risk factors in the autism spectrum: A 15-year prospective study. Autism Research. 10.1002/aur.2022.

Baghdadli A, Pascal C, Grisi S, \& Aussilloux C (2003). Risk factors for self-injurious behaviours among 222 young children with autistic disorders. Journal of Intellectual Disability Research, 47(8), 622-627. [PubMed: 14641810]

Baghdadli A, Picot MC, Pry R, Michelon C, Burzstejn C, Lazartigues A, \& Aussilloux C (2008). What factors are related to a negative outcome of self-injurious behaviour during childhood in pervasive developmental disorders? Journal of Applied Research in Intellectual Disabilities, 21(2), 142-149.

Baghdadli A, Pry R, Michelon C, \& Rattaz C (2014). Impact of autism in adolescents on parental quality of life. Quality of life research, 23(6), 1859-1868. [PubMed: 24504623]

Bal VH, Kim S-H, Cheong D, \& Lord C (2015). Daily living skills in individuals with autism spectrum disorder from 2 to 21 years of age. Autism, 19(7), 774-784. [PubMed: 25922445]

Billstedt E, Carina Gillberg I, \& Gillberg C (2007). Autism in adults: Symptom patterns and early childhood predictors. Use of the DISCO in a community sample followed from childhood. Journal of Child Psychology and Psychiatry, 48(11), 1102-1110. [PubMed: 17995486]

Brunet O, Lézine I, \& Josse D (1997). Brunet-Lézine révisé: échelle de développement psychomoteur de la première enfance: BLR: Editions et applications psychologiques.

Centers for Disease Control and Prevention (CDC). (2014). Prevalence of autism spectrum disorder among children aged 8 years-autism and developmental disabilities monitoring network, 11 sites, United States, 2010. Morbidity and Mortality Weekly Report. Surveillance Summaries. 63(2), 122.

Chaidez V, Hansen RL, \& Hertz-Picciotto I (2014). Gastrointestinal problems in children with autism, developmental delays or typical development. Journal of Autism and Developmental Disorders, 44(5), 1117-1127. [PubMed: 24193577]

Chowdhury M, Benson BA, \& Hillier A (2010). Changes in restricted repetitive behaviors with age: A study of high-functioning adults with autism spectrum disorders. Research in Autism Spectrum Disorders, 4(2), 210-216.

Courtemanche AB, Black WR, \& Reese RM (2016). The relationship between pain, self-injury, and other problem behaviors in young children with autism and other developmental disabilities. American Journal on Intellectual and Developmental Disabilities, 121(3), 194-203. [PubMed: 27119211]

Craig F, Margari F, Legrottaglie AR, Palumbi R, De Giambattista C, \& Margari L (2016). A review of executive function deficits in autism spectrum disorder and attention-deficit/hyperactivity disorder. Neuropsychiatric Disease and Treatment, 12, 1191. [PubMed: 27274255]

Davis NO, \& Carter AS (2008). Parenting stress in mothers and fathers of toddlers with autism spectrum disorders: Associations with child characteristics. Journal of Autism and Developmental Disorders, 38(7), 1278. [PubMed: 18240012]

Dunn LM, Dunn LM, \& Theriault-Whalen C (1993). Échelle de vocabulaire en images Peabody: EVIP: Psycan.

Eapen V, \& Guan J (2016). Parental quality of life in autism spectrum disorder: Current status and future directions. Acta Psychopathologica, 2(1), 1-14.

Gillespie-Lynch K, Sepeta L, Wang Y, Marshall S, Gomez L, Sigman M, \& Hutman T (2012). Early childhood predictors of the social competence of adults with autism. Journal of Autism and Developmental Disorders, 42(2), 161-174. [PubMed: 22187106]

Happé F, \& Charlton RA (2012). Aging in autism spectrum disorders: A mini-review. Gerontology, 58(1), 70-78. [PubMed: 21865667]

Howlin P, Savage S, Moss P, Tempier A, \& Rutter M (2014). Cognitive and language skills in adults with autism: A 40-year follow-up. Journal of Child Psychology and Psychiatry, 55(1), 49-58. [PubMed: 23848399] 
Jones BL, \& Nagin DS (2007). Advances in group-based trajectory modeling and an SAS procedure for estimating them. Socio-logical Methods \& Research, 35(4), 542-571.

Jones BL, Nagin DS, \& Roeder K (2001). A SAS procedure based on mixture models for estimating developmental trajectories. Sociological Methods \& Research, 29(3), 374-393.

Kaufmann AS (1983). K-ABC: Kaufmann assessment battery for children: Administration and scoring manual. Circle Pines, MN: American Guidance Service.

Kinra S, Krishna KR, Kuper H, Sarma KR, Prabhakaran P, Gupta V, .. Kumar A (2014). Cohort profile: Andhra Pradesh children and parents study (APCAPS). International Journal of Epidemiology, 43(5), 1417-1424. [PubMed: 24019421]

Lord C, Rutter M, DiLavore P, \& Risi S (2002). Autism diagnostic observation schedule: ADOS: Manual. CA: Western Psychological Services Los Angeles.

Magiati I, Tay XW, \& Howlin P (2014). Cognitive, language, social and behavioural outcomes in adults with autism spectrum disorders: a systematic review of longitudinal follow-up studies in adulthood. Clinical Psychology Review, 34(1), 73-86. [PubMed: 24424351]

McGovern CW, \& Sigman M (2005). Continuity and change from early childhood to adolescence in autism. Journal of Child Psychology and Psychiatry, 46(4), 401-408. [PubMed: 15819649]

Murphy GH, Beadle-Brown J, Wing L, Gould J, Shah A, \& Holmes N (2005). Chronicity of challenging behaviours in people with severe intellectual disabilities and/or autism: A total population sample. Journal of Autism and Developmental Disorders, 35(4), 405-418. [PubMed: 16134027]

Nagin DS, \& Nagin D (2005). Group-based modeling of development. Cambridge: Harvard University Press.

Nagin DS, \& Odgers CL (2010). Group-based trajectory modeling in clinical research. Annual Review of Clinical Psychology, 6, 109-138.

Nagin DS, \& Tremblay RE (2005). What has been learned from group-based trajectory modeling? Examples from physical aggression and other problem behaviors. The Annals of the American Academy of Political and Social Science, 602(1), 82-117.

O'neill M, \& Jones RS (1997). Sensory-perceptual abnormalities in autism: A case for more research? Journal of Autism and Developmental Disorders, 27(3), 283-293. [PubMed: 9229259]

Rattaz C, Michelon C, \& Baghdadli A (2015). Symptom severity as a risk factor for self-injurious behaviours in adolescents with autism spectrum disorders. Journal of Intellectual Disability Research, 59(8), 730-741. 10.1111/jir.12177. [PubMed: 25583371]

Rattaz C, Michelon C, Munir K, \& Baghdadli A (2018). Challenging behaviours at early adulthood in autism spectrum disorders: Topography, risk factors and evolution. Journal of Intellectual Disability Research.

Renty J, \& Roeyers H (2006). Quality of life in high-functioning adults with autism spectrum disorder: The predictive value of disability and support characteristics. Autism, 10(5), 511-524. [PubMed: 16940316]

Rutter M, Le Couteur A, \& Lord C (2003). Autism diagnostic inventory-revised. Los Angeles: Western Psychological Services.

Schieve LA, Blumberg SJ, Rice C, Visser SN, \& Boyle C (2007). The relationship between autism and parenting stress. Pediatrics, 119 (Suppl 1), 114-121. 10.1542/peds.2006-2089Q.

Schopler E, Reichler RJ, Bashford A, Lansing MD, \& Marcus LM (1990). Individualized assessment of autistic and developmentally disabled children: Psychoeducational Profile Revised (PEP-R). Austin, TX: Pro-Ed.

Schopler E, Reichler RJ, \& Renner BR (2002). The childhood autism rating scale (CARS). Los Angeles: Western Psychological Services.

Shattuck PT, Seltzer MM, Greenberg JS, Orsmond GI, Bolt D, Kring S, .. Lord C (2007). Change in autism symptoms and maladaptive behaviors in adolescents and adults with an autism spectrum disorder. Journal of Autism and Developmental Disorders, 37(9), 1735-1747. [PubMed: 17146700]

Smith LE, Maenner MJ, \& Seltzer MM (2012). Developmental trajectories in adolescents and adults with autism: The case of daily living skills. Journal of the American Academy of Child \& Adolescent Psychiatry, 51(6), 622-631. [PubMed: 22632621] 
Sparrow SS, Balla DA, \& Cicchetti DV (1984). The Vineland Adaptive Behavior Scales. Circle Pines, $\mathrm{MN}$ : America Guidance Service.

Steinhausen HC, Jensen MC, \& Lauritsen MB (2016). A systematic review and meta-analysis of the long-term overall outcome of autism spectrum disorders in adolescence and adulthood. Acta Psychiatrica Scandinavica. 133(6):445-452 [PubMed: 26763353]

Stern W (1912). The psychological methods of intelligence testing. Whipple G, Trans.). Baltimore: Warwick and York.

Szatmari P, Bryson S, Duku E, Vaccarella L, Zwaigenbaum L, Bennett T, \& Boyle MH (2009). Similar developmental trajectories in autism and Asperger syndrome: From early childhood to adolescence. Journal of Child Psychology and Psychiatry, 50(12), 1459-1467. [PubMed: 19686332]

Szatmari P, Georgiades S, Duku E, Bennett TA, Bryson S, Fombonne E, ... Vaillancourt T (2015). Developmental trajectories of symptom severity and adaptive functioning in an inception cohort of preschool children with autism spectrum disorder. JAMA Psychiatry, 72(3), 276-283. [PubMed: 25629657]

Vanderschelden M (2006). Les ruptures d'unions: plus fréquentes, mais pas plus précoces. The National Institute of Statistics and Economic Studies (INSEE). In.

Wechsler D (1949). Wechsler intelligence scale for children.

Wechsler D (1967). Wechsler preschool and primary scale of intelligence-WPPSI. New York: Psychological Corporation.

Wechsler D (1974). Manual for the Wechsler intelligence scale for children, revised. New York: Psychological Corporation.

Wechsler D (2008). Wechsler adult intelligence scale-Fourth Edition (WAIS-IV). San Antonio, TX: NCS Pearson, 22, 498.

World Health Organization. (1993). The ICD-10 classification of mental and behavioural disorders: diagnostic criteria for research. 


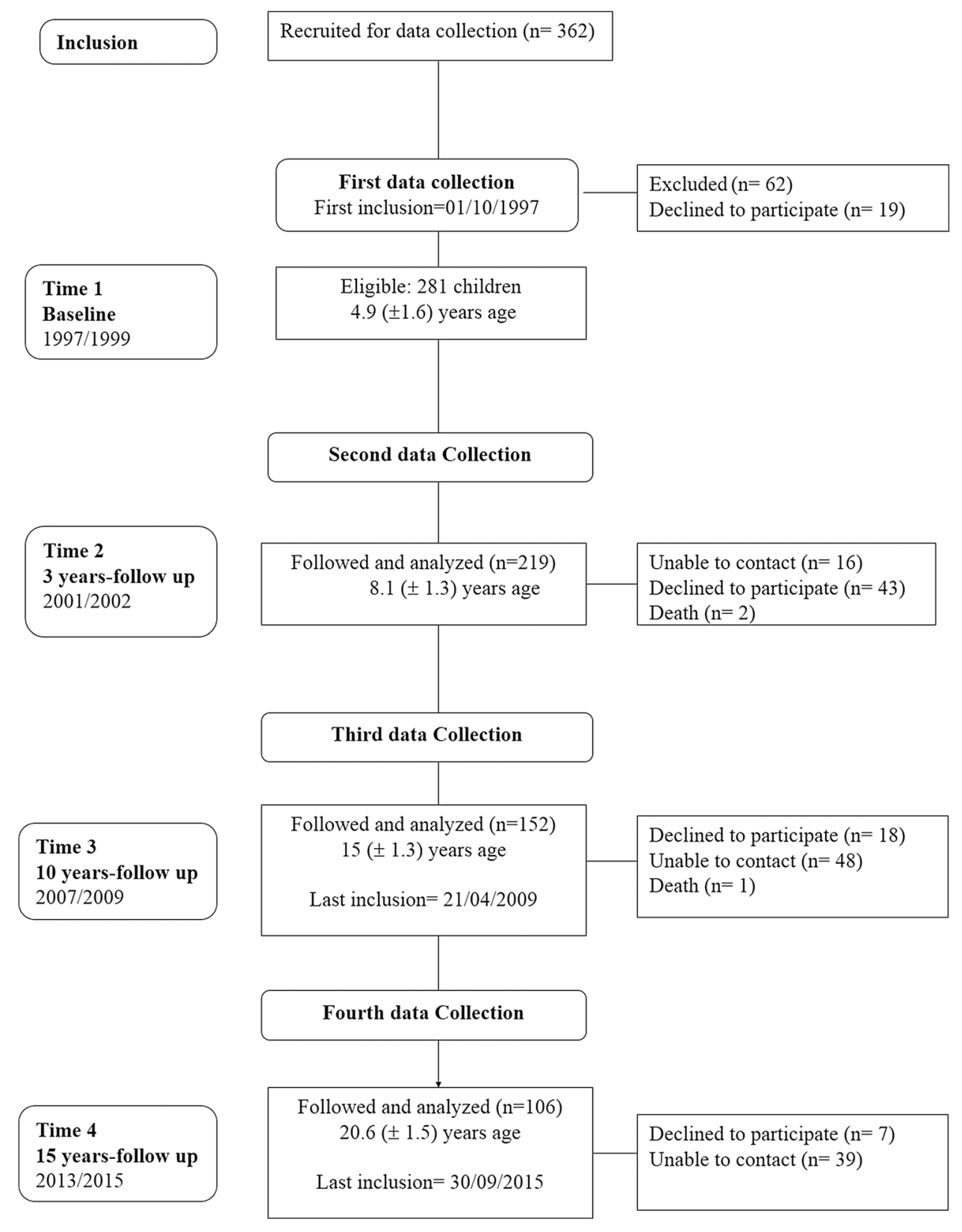

Fig. 1.

Flow chart of the EpiTED cohort 


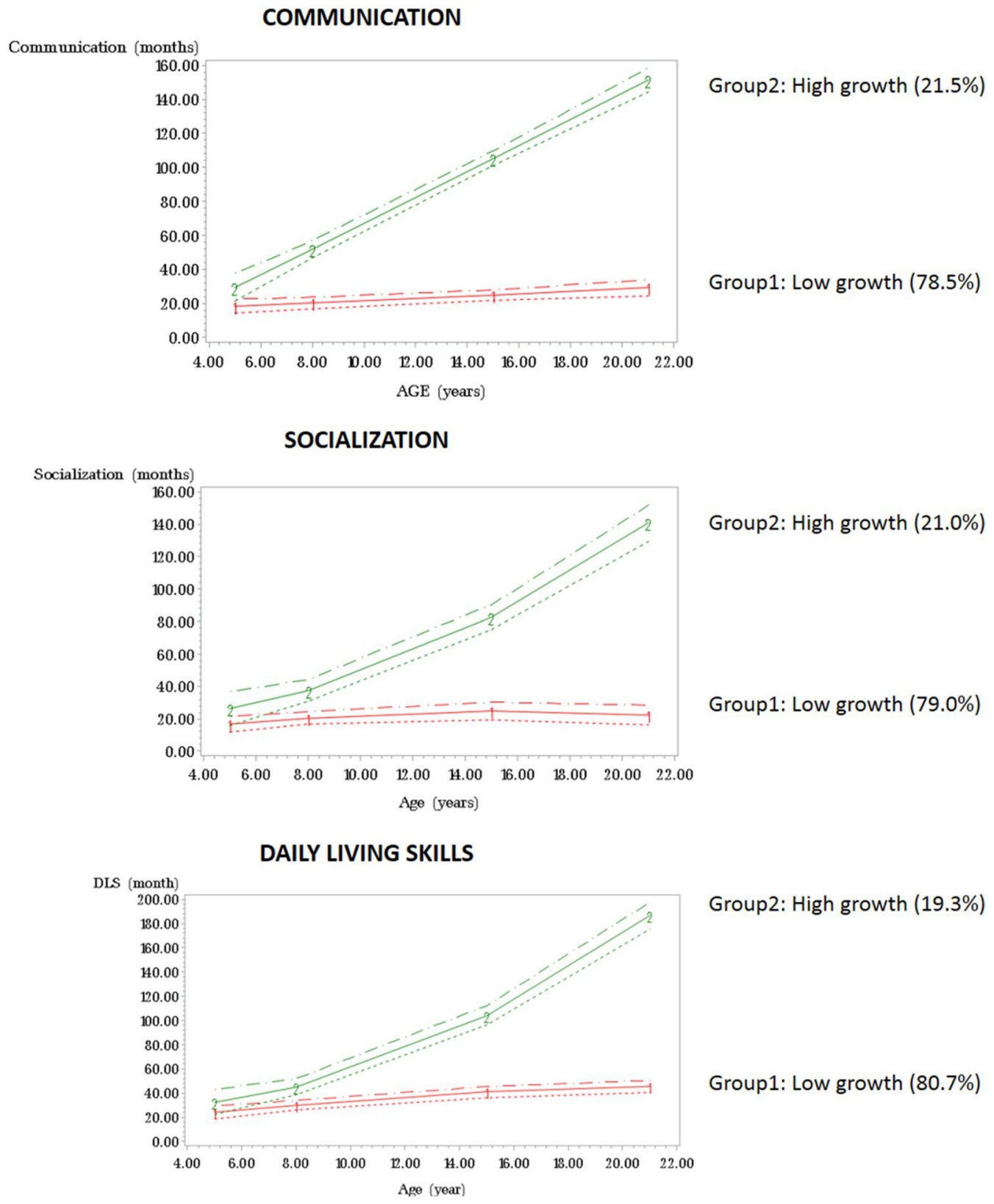

Fig. 2.

Trajectories of adaptive level through adulthood among 94 participants of the EpiTED Cohort diagnosed as children. The figure shows the mean adaptive scores (CI 95\%) over time for participants assigned to the two trajectory groups: Low growth group;...... 


\section{Table 1}

Comparison of characteristics at T1 between the patients who remained in the cohort and those lost to followup

\begin{tabular}{|c|c|c|c|}
\hline & Patients who were Followed-up & Patients lost to follow-up & \\
\hline & $\begin{array}{l}\mathrm{N}=106 \\
\text { median (IntQ*) }\end{array}$ & $\begin{array}{l}\mathrm{N}=175 \\
\text { median (IntQ) }\end{array}$ & p-value \\
\hline Inclusion age & $4.11(3.1 ; 5.1)$ & $5.3(3.1 ; 5.1)$ & 0.40 \\
\hline \multicolumn{4}{|c|}{ Adaptive behaviors (VABS) (months) } \\
\hline Communication & $15(12 ; 20)$ & $15(11 ; 21)$ & 0.30 \\
\hline Daily living skills & $23(18 ; 28)$ & $22.5(18 ; 31)$ & 0.90 \\
\hline Socialization & $14(10 ; 20)$ & $15(9 ; 22)$ & 0.80 \\
\hline \multirow[t]{2}{*}{ CARS total score } & $35.75(29.5 ; 40.0)$ & $35.5(30.5 ; 41.5)$ & 0.80 \\
\hline & Patients who were followed up (\%) & Patients lost to follow-up (\%) & $\mathrm{p}$-value \\
\hline \multicolumn{4}{|l|}{ Sex } \\
\hline Male & 85 & 75 & $0.05^{* * *}$ \\
\hline Female & 15 & 25 & \\
\hline \multicolumn{4}{|c|}{ Verbal expressive language } \\
\hline Functional language & 21 & 26 & 0.60 \\
\hline Mute & 55 & 52 & \\
\hline Words & 25 & 22 & \\
\hline \multicolumn{4}{|l|}{ Epilepsy } \\
\hline Absence & 95 & 90 & 0.10 \\
\hline Presence & 5 & 10 & \\
\hline \multicolumn{4}{|c|}{ Congenital or chromosomal abnormalities } \\
\hline Absence & 98 & 95 & 0.30 \\
\hline Presence & 2 & 5 & \\
\hline \multicolumn{4}{|c|}{ Perinatal and prenatal condition } \\
\hline Absence & 97 & 93 & 0.10 \\
\hline Presence & 2.8 & 7 & \\
\hline \multicolumn{4}{|c|}{ Parents' socio-economic level } \\
\hline High & 24 & 27 & 0.80 \\
\hline Middle & 43 & 41 & \\
\hline Low & 33 & 32 & \\
\hline
\end{tabular}


Table 2

EpiTED summary of measurements

\begin{tabular}{|c|c|c|c|c|}
\hline & Time 1 & Time 2 & Time 3 & Time 4 \\
\hline \multicolumn{5}{|l|}{ Socio-demographic data } \\
\hline \multicolumn{5}{|l|}{ Self-reported questionnaire measures } \\
\hline \multicolumn{5}{|l|}{ Parents } \\
\hline Gender & $\checkmark$ & & & \\
\hline Place of residence & $\checkmark$ & $\checkmark$ & $\checkmark$ & $\checkmark$ \\
\hline Environment (rural/urban) & & & $\checkmark$ & $\checkmark$ \\
\hline Marital status & $\checkmark$ & $\checkmark$ & $\checkmark$ & $\checkmark$ \\
\hline Siblings & $\checkmark$ & $\checkmark$ & $\checkmark$ & $\checkmark$ \\
\hline Child rank & $\checkmark$ & $\checkmark$ & $\checkmark$ & $\checkmark$ \\
\hline Number of children living at home & $\checkmark$ & $\checkmark$ & $\checkmark$ & $\checkmark$ \\
\hline Socio-economic status & $\checkmark$ & $\checkmark$ & $\checkmark$ & $\checkmark$ \\
\hline Educational level & & & & $\checkmark$ \\
\hline Family resources index & $\checkmark$ & $\checkmark$ & & \\
\hline Membership of parental association & & & & $\checkmark$ \\
\hline Knowledge of autism & & & & $\checkmark$ \\
\hline Parental training in the field of ASD & & & & $\checkmark$ \\
\hline Financial aid & & & & $\checkmark$ \\
\hline \multicolumn{5}{|l|}{ Patients } \\
\hline Type of living & $\checkmark$ & $\checkmark$ & $\checkmark$ & $\checkmark$ \\
\hline Schooling & $\checkmark$ & $\checkmark$ & $\checkmark$ & $\checkmark$ \\
\hline School assistant & $\checkmark$ & & $\checkmark$ & $\checkmark$ \\
\hline Specialized service & $\checkmark$ & $\checkmark$ & $\checkmark$ & $\checkmark$ \\
\hline Therapy with a private professional & & & $\checkmark$ & $\checkmark$ \\
\hline Occupational activities & & & & $\checkmark$ \\
\hline Measures of goods protection & & & & $\checkmark$ \\
\hline Marital status & & & & $\checkmark$ \\
\hline Familial status (with or without child,...) & & & & $\checkmark$ \\
\hline Place of residence & & & & $\checkmark$ \\
\hline \multicolumn{5}{|l|}{ Clinical data } \\
\hline \multicolumn{5}{|l|}{ Data collected by interview } \\
\hline Diagnosis & $\checkmark$ & $\checkmark$ & $\checkmark$ & $\checkmark$ \\
\hline ICD 10 criteria & $\checkmark$ & $\checkmark$ & $\checkmark$ & $\checkmark$ \\
\hline Chronological age & $\checkmark$ & $\checkmark$ & $\checkmark$ & $\checkmark$ \\
\hline Weight & & & $\checkmark$ & $\checkmark$ \\
\hline Height & & & $\checkmark$ & $\checkmark$ \\
\hline Umbilical perimeter & & & & $\checkmark$ \\
\hline Age of sitting position & $\checkmark$ & & & \\
\hline Age of independent walking & $\checkmark$ & & & \\
\hline First words & $\checkmark$ & & & \\
\hline
\end{tabular}




\begin{tabular}{lllll} 
First sentences & $\checkmark$ & & & \\
Medical history & $\checkmark$ & & & \\
Associated medical conditions & & & $\checkmark$ & $\checkmark$ \\
Age of first disorders & $\checkmark$ & & & \\
Age at first psychiatric advice & $\checkmark$ & & & \\
Age at first intervention & $\checkmark$ & & $\checkmark$ & \\
Age at first diagnosis & $\checkmark$ & & $\checkmark$ & \\
Daily use of drug (frequency, type) & $\checkmark$ & $\checkmark$ & $\checkmark$ & $\checkmark$ \\
\hline & Time 1 & Time 2 & Time 3 & Time 4
\end{tabular}

Cognitive and mental health data

Data collected by standardized procedure ADI-R

ADOS 1-2 (module 1/2/3/4)

VABS (version 1 or 2)

Best estimate DQ

Symptom severity (CARS)

Verbal expressive language level

Receptive vocabulary level (EVIP)

Self-reported questionnaire measures

Parental quality of life (Par-DD-QoL)

VAS-children's quality of life

VAS-parental satisfaction regarding interventions

Behavioral problems (ABC)

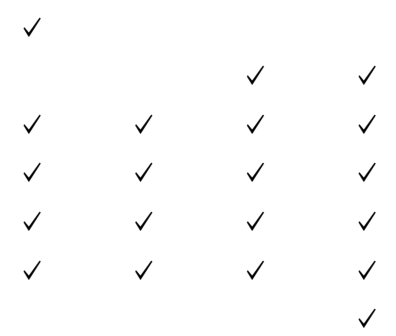




\section{Table 3}

Persistent participants characteristics in function of diagnosis status at each time of follow-up for participants still present at $\mathrm{T} 4(\mathrm{~N}=106)$

\begin{tabular}{|c|c|c|c|c|c|c|c|c|c|c|c|c|}
\hline & \multirow{2}{*}{\multicolumn{2}{|c|}{$\begin{array}{l}\text { T1: Baseline } \\
4.4 \pm 1.3 \text { years }\end{array}$}} & \multirow[b]{3}{*}{$\begin{array}{l}\text { p- } \\
\text { value }\end{array}$} & \multirow{2}{*}{\multicolumn{2}{|c|}{$\begin{array}{l}\text { T2 : } 3 \text { years follow-up } \\
8.1 \pm 1.4 \text { years }\end{array}$}} & \multirow[b]{3}{*}{$\begin{array}{l}\text { p- } \\
\text { value }\end{array}$} & \multirow{2}{*}{\multicolumn{2}{|c|}{$\begin{array}{l}\text { T3 : } 10 \text { years follow-up } \\
14.9 \pm 1.6 \text { years }\end{array}$}} & & \multirow{2}{*}{\multicolumn{2}{|c|}{$\begin{array}{l}\text { T4 : } 15 \text { years follow-up } \\
20.6 \pm 1.5 \text { years }\end{array}$}} & \multirow[b]{3}{*}{$\begin{array}{l}\text { p- } \\
\text { value }\end{array}$} \\
\hline & & & & & & & & & & & & \\
\hline & $\begin{array}{l}1 . \\
\text { Childhood } \\
\text { autism }(\mathrm{N} \\
=94)\end{array}$ & $\begin{array}{l}2 . \\
\text { Atypical } \\
\text { autism } \\
(N=12)\end{array}$ & & $\begin{array}{l}\text { 1. } \\
\text { Childhood } \\
\text { autism (N } \\
=94)\end{array}$ & $\begin{array}{l}2 . \\
\text { Atypical } \\
\text { autism } \\
(N=12)\end{array}$ & & $\begin{array}{l}\text { 1. } \\
\text { Childhood } \\
\text { autism (N } \\
=80)\end{array}$ & $\begin{array}{l}2 . \\
\text { Atypical } \\
\text { autism } \\
(N=21) \\
\& \text { Out of } \\
\text { AS }(N= \\
5)^{a}\end{array}$ & $\begin{array}{l}\text { p- } \\
\text { value }\end{array}$ & $\begin{array}{l}\text { 1. } \\
\text { Childhood } \\
\text { autism (N } \\
=82)\end{array}$ & $\begin{array}{l}2 . \\
\text { Atypical } \\
\text { autism } \\
(N=16) \\
\& \text { Out } \\
\text { of AS } \\
(N=6)^{a}\end{array}$ & \\
\hline $\begin{array}{l}\text { CARS total } \\
\text { score }^{b}(\text { mean } \pm \\
\text { SD) }\end{array}$ & $36.0 \pm 5.9$ & $31.7 \pm 6.2$ & .01 & $33.3 \pm 7.7$ & $\begin{array}{l}26.7 \\
\pm 7.5\end{array}$ & 0.006 & $36.4 \pm 7.7$ & $25.6 \pm 4.5$ & $\begin{array}{l}<. \\
0001\end{array}$ & $37.7 \pm 8.6$ & $\begin{array}{l}23.4 \\
\pm 3.6\end{array}$ & $\begin{array}{l}<. \\
0001\end{array}$ \\
\hline \multicolumn{13}{|c|}{ Best estimate DQ $(\%, \mathrm{~N})$} \\
\hline $\begin{array}{l}\text { Severe ID } \\
(\mathrm{DQ}<40)\end{array}$ & $52.7(49)$ & $33.3(4)$ & .1 & $53.2(50)$ & $25.0(3)$ & 0.002 & $66.3(53)$ & $30.8(8)$ & 0.007 & $78.2(61)$ & $22.7(5)$ & $\begin{array}{l}<. \\
0001\end{array}$ \\
\hline $\begin{array}{r}\text { Moderate ID } \\
(40 \leq \mathrm{DQ}<55)\end{array}$ & $29(27)$ & $33.3(4)$ & & $16.0(15)$ & $25.0(3)$ & & $7.5(6)$ & $19.2(5)$ & & $6.4(5)$ & $4.5(1)$ & \\
\hline $\begin{aligned} & \text { Mild ID (55 } \\
&\leq \mathrm{DQ}<70)\end{aligned}$ & $10.8(10)$ & $33.3(4)$ & & $10.6(10)$ & $50.0(6)$ & & $3.8(3)$ & $11.5(3)$ & & $1.3(1)$ & $13.6(3)$ & \\
\hline$\underset{70)}{\text { No ID (DQ } \geq}$ & $7.5(7)$ & & & $20.2(19)$ & & & $22.5(18)$ & $38.5(10)$ & & $14.1(11)$ & $\begin{array}{l}59.1 \\
(13)\end{array}$ & \\
\hline \multicolumn{13}{|c|}{$\operatorname{Vineland}^{c}($ month$)($ mean $\pm \mathrm{SD})$} \\
\hline Communication & $17.3 \pm 10.1$ & $\begin{array}{l}27.4 \pm 16 \\
.2\end{array}$ & .04 & $27.5 \pm 19.5$ & $\begin{array}{l}42.6 \\
\pm 21.5\end{array}$ & 0.01 & $35.1 \pm 30.9$ & $83.2 \pm 50.2$ & 0.003 & $39.3 \pm 43.2$ & $\begin{array}{l}117.9 \\
\pm 55.1\end{array}$ & $\begin{array}{l}<. \\
0001\end{array}$ \\
\hline Socialization & $15.6 \pm 10.7$ & $\begin{array}{l}25.6 \\
\pm 17.2\end{array}$ & .01 & $24.2 \pm 15.9$ & $\begin{array}{l}42.2 \\
\pm 22.7\end{array}$ & 0.003 & $28.4 \pm 23.5$ & $\begin{array}{l}66.5 \\
\pm 39.75\end{array}$ & $\begin{array}{l}<. \\
0001\end{array}$ & $28.8 \pm 37.4$ & $\begin{array}{l}117.7 \\
\pm 55.2\end{array}$ & $\begin{array}{l}<. \\
0001\end{array}$ \\
\hline $\begin{array}{l}\text { Daily living } \\
\text { skills }\end{array}$ & $23.6 \pm 9.8$ & $\begin{array}{l}32.5 \\
\pm 12.2\end{array}$ & .01 & $34.4 \pm 14.0$ & $\begin{array}{l}55.1 \\
\pm 29.7\end{array}$ & 0.002 & $47.0 \pm 28.0$ & $76.2 \pm 33.5$ & $\begin{array}{l}<. \\
0001\end{array}$ & $53.2 \pm 39.7$ & $\begin{array}{l}152.1 \\
\pm 64.9\end{array}$ & $\begin{array}{l}<. \\
0001\end{array}$ \\
\hline $\begin{array}{l}\text { Chronological } \\
\text { age (years) } \\
(\text { mean } \pm \text { SD) }\end{array}$ & $4.3 \pm 1.25$ & $5.0 \pm 1.0$ & .07 & $8.0 \pm 1.4$ & $8.6 \pm 1.1$ & 0.2 & $14.9 \pm 1.6$ & $14.9 \pm 1.7$ & 6 & $20.6 \pm 1.4$ & $\begin{array}{l}20.1 \\
\pm 1.6\end{array}$ & .2 \\
\hline \multicolumn{13}{|c|}{ Expressive language $\%(\mathrm{~N})$} \\
\hline Sentences & $17.0(16)$ & $50.0(6)$ & .006 & $42.6(40)$ & $75.0(9)$ & 0.1 & $42.5(34)$ & $80.8(21)$ & .003 & $37.8(31)$ & $\begin{array}{l}95.5 \\
(21)\end{array}$ & $\begin{array}{l}<. \\
0001\end{array}$ \\
\hline Words & $23.4(22)$ & $33.3(4)$ & & $23.4(22)$ & $16.7(2)$ & & $20.0(16)$ & $7.7(2)$ & & $23.2(19)$ & & \\
\hline Mute & $59.6(56)$ & $16.7(2)$ & & $34.0(32)$ & $8.3(1)$ & & $37.5(30)$ & $11.5(3)$ & & $39.0(32)$ & $4.5(1)$ & \\
\hline \multicolumn{13}{|c|}{ Parents' socio-economical status (SES) ${ }^{d}(\%, \mathrm{~N})$} \\
\hline Low & $36.2(34)$ & $8.3(1)$ & .05 & $32.6(28)$ & $8.3(1)$ & .2 & $33.8(27)$ & $53.8(14)$ & .2 & $27.2(22)$ & $27.3(6)$ & .2 \\
\hline Middle & $39.4(37)$ & $75.0(9)$ & & $41.9(36)$ & $66.7(8)$ & & $23.8(19)$ & $15.4(4)$ & & $24.7(20)$ & $9.1(2)$ & \\
\hline High & $24.5(23)$ & $16.7(2)$ & & $32.6(28)$ & $25.0(3)$ & & $42.5(34)$ & $30.8(8)$ & & $48.1(39)$ & $\begin{array}{l}63.6 \\
(14)\end{array}$ & \\
\hline
\end{tabular}

Significant associations $(\mathrm{p}$-value $<.05)$ are presented in bold

${ }^{a}$ Diagnoses of atypical and out of autism spectrum were grouped because there was no difference between the two groups

$b_{\text {CARS total score }}=30-36.5$ : mild autism; CARS total score $=37-60:$ severe autism

$c_{\text {Vineland normative mean }}=100 \pm 15$

J Autism Dev Disord. Author manuscript; available in PMC 2020 June 01. 


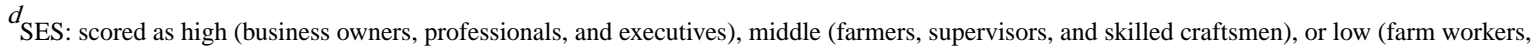
laborers, and service employees) 
Table 4

challenging behaviors at adulthood (Rattaz et al. 2018)

\begin{tabular}{|c|c|c|c|c|c|c|c|c|}
\hline & Irritability & & Lethargy & & Stereotypy & & Hyperactivity & \\
\hline & Median (IntQ) & p-value & Median (IntQ) & $\begin{array}{l}\text { p- } \\
\text { value }\end{array}$ & Median (IntQ) & p-value & Median (IntQ) & p-value \\
\hline \multicolumn{9}{|l|}{ Best estimate DQ } \\
\hline $\begin{array}{l}\text { 1. Severe } \\
\text { Intellectual } \\
\text { Disability (DQ < } \\
\text { 40) }\end{array}$ & $24.4(11.1 ; 42.2)$ & 0.0001 & $\begin{array}{l}31.25 \\
(14.6 ; 47.9)\end{array}$ & 0.3 & $38.1(14.3 ; 57.1)$ & 0.002 & $29.2(12.5 ; 45.8)$ & 0.0001 \\
\hline \begin{tabular}{l}
\multicolumn{1}{c}{ 2. Moderate } \\
Intellectual \\
Disability $(40 \leq$ \\
DQ < 55)
\end{tabular} & $12.2(8.9 ; 17.8)$ & & $29.2(22.9 ; 35.4)$ & & $16.7(9.5 ; 38.1)$ & & $12.5(8.3 ; 16.7)$ & \\
\hline $\begin{array}{l}\quad \text { 3. Mild } \\
\text { Intellectual } \\
\text { Disability }(55 \leq \\
\text { DQ }<70)\end{array}$ & $4.4(1.1 ; 18.9)$ & & $\begin{array}{l}17.7 \\
(6.25 ; 31.25)\end{array}$ & & $23.8(9.5 ; 38.1)$ & & $13.5(3.1 ; 29.2)$ & \\
\hline $\begin{array}{l}\quad \text { 4. Without } \\
\text { Intellectual } \\
\text { Disability (DQ } \geq \\
\text { 70) }\end{array}$ & $4.4(0.0 ; 13.3)$ & & $25.0(8.3 ; 41.7)$ & & $14.3(0.0 ; 23.8)$ & & $8.3(4.2 ; 14.6)$ & \\
\hline \multicolumn{9}{|c|}{ Expressive language } \\
\hline Speech & $13.3(4.4 ; 28.9)$ & 0.009 & $27.1(12.5 ; 45.8)$ & 0.4 & $19.05(9.5 ; 38.1)$ & 0.005 & $14.6(6.25 ; 31.25)$ & 0.001 \\
\hline No speech & $26.7(12.2 ; 42.2)$ & & $33.3(14.6 ; 45.8)$ & & $47.6(11.9 ; 57.1)$ & & $33.3(15.6 ; 51.0)$ & \\
\hline \multicolumn{9}{|l|}{ Gender } \\
\hline Man & $17.8(4.4 ; 33.3)$ & 0.7 & $27.1(12.5 ; 45.8)$ & 0.8 & $23.8(9.5 ; 47.6)$ & 0.5 & $18.75(8.3 ; 37.5)$ & 0.6 \\
\hline Woman & $22.2(2.2 ; 44.4)$ & & $27.1(10.4 ; 45.8)$ & & $38.1(0.0 ; 52.4)$ & & $14.6(8.3 ; 33.3)$ & \\
\hline \multicolumn{9}{|c|}{ Gastrointestinal disorders } \\
\hline Absence & $15.6(4.4 ; 31.1)$ & 0.1 & $25.0(12.5 ; 41.7)$ & 0.2 & $19.1(9.5 ; 38.1)$ & 0.002 & $16.7(6.25 ; 37.5)$ & 0.2 \\
\hline Presence & $20.0(11.1 ; 35.6)$ & & $33.3(12.5 ; 47.9)$ & & $42.9(19.1 ; 57.1)$ & & $21.9(12.5 ; 43.75)$ & \\
\hline \multicolumn{9}{|l|}{ Sleeping disorders } \\
\hline Absence & $11.1(2.2 ; 31.1)$ & 0.005 & $25.0(14.6 ; 41.7)$ & 0.4 & $14.3(9.5 ; 38.1)$ & 0.002 & $14.6(6.3 ; 31.3)$ & 0.02 \\
\hline Presence & $24.4(13.3 ; 40.0)$ & & $33.3(10.4 ; 47.9)$ & & $38.1(19.1 ; 57.1)$ & & $22.9(12.5 ; 47.9)$ & \\
\hline \multicolumn{9}{|l|}{ Epilepsy } \\
\hline Absence & $15.6(4.4 ; 33.3)$ & 0.4 & $29.2(16.7 ; 45.8)$ & 0.3 & $23.8(9.5 ; 47.6)$ & 0.8 & $16.7(8.3 ; 37.5)$ & 0.3 \\
\hline \multirow[t]{2}{*}{ Presence } & $22.2(6.7 ; 40.0)$ & & $12.5(8.3 ; 35.4)$ & & $23.8(4.8 ; 57.1)$ & & $33.3(8.3 ; 47.9)$ & \\
\hline & $\mathrm{r}$ (spearman) & $\mathrm{p}$-value & $\mathrm{r}$ (spearman) & $\mathrm{p}$-value & $\mathrm{r}$ (spearman) & $\mathrm{p}$-value & $\mathrm{r}$ (spearman) & $\mathrm{p}$-value \\
\hline $\begin{array}{l}\text { Symptom } \\
\text { severity }\end{array}$ & 0.52 & 0.0001 & 0.32 & 0.001 & 0.50 & 0.0001 & 0.54 & 0.0001 \\
\hline
\end{tabular}

Significant associations (p-value < .05) are presented in bold 